\title{
Assessment of Epidemiological Profile and Clinical Characteristics of Head and Neck Cancers among Patients of Tertiary Hospital in North Western India: A 10-Year Retrospective Study
}

\author{
Shveta Mahajan ${ }^{1}$, Rajeev Gupta ${ }^{2}$, Vanita Sareen ${ }^{3}$, Vikas Kakar ${ }^{4}$ \\ ${ }^{1}$ Dental Surgeon, JK Health Services, PHC Lakhanpur, Jammu and Kashmir, ${ }^{2}$ Associate Professor, Department of medicine, \\ SGRDIMSR, Mehta Road, PO Vallah, Sri Amritsar, Punjab, ${ }^{3}$ Professor, Department of ENT, SGRDIMSR, Mehta Road, PO Vallah, \\ Sri Amritsar, Punjab, ${ }^{4}$ Associate Professor, Department of Surgery, SGRDIMSR, Mehta Road, PO Vallah, Sri Amritsar, Punjab, \\ India
}

Corresponding author: Rajeev Gupta, Associate Professor, Department of Medicine, SGRDIMSR, Mehta Road, PO Vallah, Sri Amritsar, Punjab, India

DOI: http://dx.doi.org/10.21276/ijcmsr.2019.4.4.47

How to cite this article: Shveta Mahajan, Rajeev Gupta, Vanita Sareen, Vikas Kakar. Assessment of epidemiological profile and clinical characteristics of head and neck cancers among patients of tertiary hospital in north western india: a 10-year retrospective study. International Journal of Contemporary Medicine Surgery and Radiology. 2019;4(4):D195-D199.

\section{A B S T R A C T}

Introduction: Head and neck cancers constitute main form of cancer in India, leading to $23 \%$ of all cancers in males and $6 \%$ in females. In India, this imbalance may be due to the higher incidence of these cancers compared to other common malignancies may be due to the consumption of smoking, chewing tobacco and alcohol in various forms. Within the country, the spectrum of head and neck cancer varies from place to place because of significant variation in regional risk factors. Hence, the aim of the present study was to assess the epidemiological profile and clinical characteristics of head and neck cancers among patients attending tertiary hospital in North Western region.

Material and Methods: The present was a retrospective study which was conducted among the patients attended the tertiary hospital centre from the period of June 2009-May 2019. Data was recorded for such patients and details were entered in standardized questionnaire, such as age, sex, site involved, followed by smoking, alcohol, chewing habits, and other clinical details. Patients on the basis of histopathology were categorized into squamous cell carcinoma and other malignancy.

Results: In the present study, the most common age group found was $51-60$ years i.e. $29.4 \%$ of the subjects followed by 41 50 years i.e. $25.5 \%$ of the subjects. The least age group found was $>80$ years i.e. $2.98 \%$. The majority of the subjects were males i.e. $90.4 \%$ as compared to females i.e. 9.51\%. About $32.1 \%$ were males who belonged to the age group 51-60 years and females were $39.2 \%$ who belonged to the age group 51-60 years. Smoking alone was found to be the most common risk factor observed in majority of the cases in causing cancer at the base of the tongue (35), tonsillar fossae (51) followed by larynx (39).

Conclusion: Due to rise in the number of head and neck cancers, there is high morbidity and mortality in Indian population due to the involvement of the factors such as smoking, consumption of tobacco in its various forms and alcohol. Hence, there should be awareness about cancer and prevention programmes to prevent and increase the quality of life.

Keywords: Head and Neck Cancer, Prevalence, Larynx, Buccal Mucosa, Retrospective

\section{INTRODUCTION}

Head and neck cancer (HNC) is one of the six leading cancer worldwide with annual incidence more than 550,000 cases, of which around 300,000 deaths occur every year. It accounted for about $90 \%$ of all $\mathrm{HNC}$ cases and usually develops in sixth to seventh decades of life. However, from the previous literature it was revealed that it has developed in younger age groups in different parts of world including India, China, USA, and Europe. HNSCC incidence rate in patients below 40 years has reached $0.4 \%-3.6 \%$. The most common locations where HNSCC arises are the oral cavity, oropharynx, larynx, and hypopharynx. ${ }^{1,2}$

Oral cancers are most common amongst all head and neck squamous cell cancers (HNSCC). The main risk factors associated with HNSCC are lifestyle factors such as chewing tobacco, alcohol consumption, smoking and environmental factors. This is mainly due to the consumption of tobacco, areca nut, alcohol, etc. HNSCC in the developing world differ from those in the Western world in terms of age, site of disease, etiology, and molecular biology. Poverty, illiteracy, 
advanced stage at presentation, lack of access to health care, and poor treatment infrastructure pose a major challenge in management of these cancers. ${ }^{3}$ The Cancer Atlas project by the Indian Council for Medical Research (ICMR) revealed that about $90 \%$ of the oral cancer patients in rural areas belong to the lower or lower-middle socio-economic class, and $3.6 \%$ are below the poverty line. ${ }^{4,5}$

In a report presented by World Health Organization, it was revealed that in India, cancer has been growing at the rate of $11 \%$ annually due to widespread tobacco consumption. In a study done by Sankaranarayanan et al reported that a significant increased risk of cancers of the tongue and the floor of the mouth in association with tobacco chewing, bidi smoking, combined bidi and cigarette smoking and alcohol consumption were found. Other important risk factors are human papillomavirus (HPV) and Epstein-Barr virus which are adjuvant carcinogens and act as distinct promotion factors. ${ }^{6,7}$

As a result of the constant habit of smokeless tobacco mixed with lime against the back ground of poor oral hygiene on an individual who also takes tobacco and alcohol, there could be a possibility of high infection of HPV among this population especially on the stain and abraded oropharynx mucosa.

Recent researches suggested that there may be possibility that HPV may be linked with some oropharyngeal and OC cases. HPV has been detected in up to $22 \%$, and HPV 18 has been found in up to $14 \%$ of OC cases. ${ }^{8}$ The infrastructure for cancer management is largely inadequate in India.

It is a heterogeneous disease, with various types of tumours developed in the hypopharynx, oropharynx, lip, oral cavity, nasopharynx, or larynx. The disease group as a whole is associated with different epidemiology, etiology, and therapy. Globally, it is the sixth most common neoplasia and accounts for $6 \%$ of all cases, being responsible approximately for $1 \%-2 \%$ of deaths due to tumour. Given the complexities of head and neck cancer (HNC), treatment decisions have to be taken by multidisciplinary teams (MDTs) with training not only in treatment but also in supportive care (considering swallowing, nutritional, dental, and voice impairment due to the effects of clinical intervention). ${ }^{9,10}$

For the management of head and neck cancers, there is a major challenge for lower socio-economic class in developing countries. Also, there is scarcity of infrastructure and health care workers, illiteracy and lack of awareness among the general population about the side effects of tobacco, and prevalent cultural beliefs lead to delays in seeking treatment and, thus, advanced-stage presentation of disease. New cancer control programs have been implemented in developing countries with the goals of achieving prevention, strengthening the available cancer treatment facilities, and early diagnosis and treatment in response to the increase in the number of cancer patients. ${ }^{11}$

Within the country, the spectrum of head and neck cancer differs from place to place and also site-specific data from different parts of the country gives the various trends and provide clues to the etiological factors responsible for this significant variation. Hence, the aim of the present study was to assess the epidemiological profile and clinical characteristics of head and neck cancers among patients attending tertiary hospital in North Western India.

\section{MATERIAL AND METHODS}

The present study was a retrospective study which was conducted among the patients attending the tertiary hospital centre from the period of June 2009-May 2019. Data regarding patients were entered in standardized questionnaire related to age, sex, site involved, smoking, alcohol and chewing habits, and other demographic details. Patients on the basis of histopathology were categorized into squamous cell carcinoma and other malignancies. Head and neck region were classified according to the International Classification of disease coding system given by $\mathrm{WHO}^{12}$ (9th revision) using ICD codes from 140 to 202. All biopsies performed in the hospital formed the basis of all further analysis which was used as calculations in the further analysis.

\section{STATISTICAL ANALYSIS}

The data was entered into the Microsoft excel sheet and was analyzed with the help of SPSS software version 21. Descriptive statistics such as percentage was performed and was presented in the form of tables and graphs. Inferential statistics such as chi-square test was performed. A p value of 0.05 was considered to be statistically significant.

\section{RESULTS}

In the present study, the most common age group found was

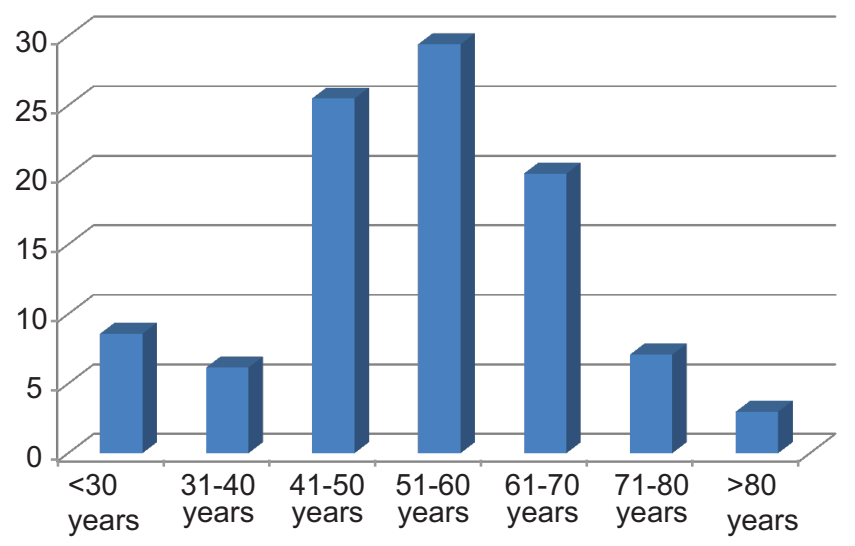

Graph-1: Shows the distribution of data based on the age groups among the study subjects

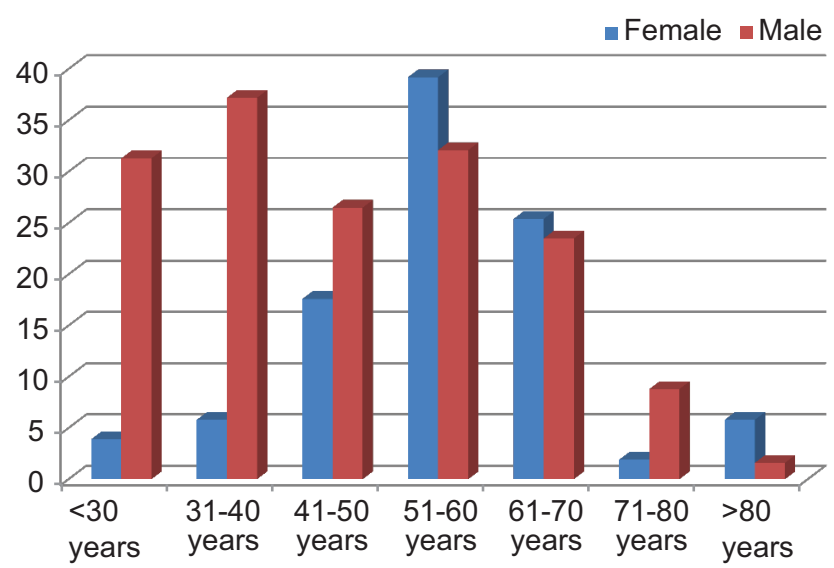

Graph-2: Shows the distribution of data based on the gender among the study subjects 
51-60 years i.e. $29.4 \%$ of the subjects, followed by $41-50$ years i.e. $25.5 \%$ of the subjects. The least age group found was $>80$ years i.e. $2.98 \%$ (Table 1 and Graph 1 ). The majority of the subjects were males i.e. $90.4 \%$ as compared to females i.e. $9.51 \%$. About $32.1 \%$ were males who belonged to the age group 51-60 years and females were $39.2 \%$ who belonged to the age group 51-60 years (Table 2 and Graph 2). According to the site of tumour, the majority of the subjects had cancers in the oral cavity that belonged to the age group of $31-40$

\begin{tabular}{|l|c|c|}
\hline Age Groups & Total & Percentage \\
\hline$<30$ years & 46 & $8.58 \%$ \\
\hline $31-40$ years & 33 & $6.15 \%$ \\
\hline $41-50$ years & 137 & $25.5 \%$ \\
\hline $51-60$ years & 158 & $29.4 \%$ \\
\hline $61-70$ years & 108 & $20.1 \%$ \\
\hline $71-80$ years & 38 & $7.08 \%$ \\
\hline$>80$ years & 16 & $2.98 \%$ \\
\hline Total & 536 & $100 \%$ \\
\hline \multicolumn{2}{|c|}{ Table-1: Shows the distribution of data based on the age } \\
groups among the study subjects \\
\hline
\end{tabular}

years age group followed by oropharynx where subjects of 51-60 years age group were involved. The majority of the subjects with age group of 41-50 years were commonly involved with larynx. The maximum number of subjects with age group 51-60 years was seen with hypopharynx followed by 61-70 years age group. The nose and PNS were most commonly involved with 41-50 years age group followed by nasopharynx. These differences were found to be highly statistically significant at $p$ value 0.001 (Table 3 ). In majority of the subjects, smoking, chewing tobacco and alcohol was found to be the most common risk factor in causing cancer at the buccal mucosa (63). Smoking alone was found to be the most common risk factor observed in majority of the cases in causing cancer at the base of the tongue (35), tonsillar fossae (51) followed by larynx (39). This difference was found to be statistically significant at $\mathrm{p}$ value 0.001 (Table 4).

\section{DISCUSSION}

Developing countries, especially Southeast Asia, have major impact of Head and neck cancers. Males are affected comparatively more than females as habits related to tobacco, areca nut, alcohol, etc. are more seen in males. It

\begin{tabular}{|c|c|c|c|c|c|}
\hline \multirow[t]{2}{*}{ Age groups } & \multicolumn{2}{|c|}{ Gender } & \multirow[t]{2}{*}{ Total } & \multicolumn{2}{|c|}{ Percentage } \\
\hline & Females & Males & & Females & Males \\
\hline$<30$ years & 2 & 16 & 18 & $3.9 \%$ & $31.3 \%$ \\
\hline $31-40$ years & 3 & 19 & 22 & $5.8 \%$ & $37.2 \%$ \\
\hline $41-50$ years & 9 & 129 & 138 & $17.6 \%$ & $26.5 \%$ \\
\hline $51-60$ years & 20 & 156 & 176 & $39.2 \%$ & $32.1 \%$ \\
\hline $61-70$ years & 13 & 114 & 127 & $25.4 \%$ & $23.5 \%$ \\
\hline $71-80$ years & 1 & 43 & 44 & $1.9 \%$ & $8.8 \%$ \\
\hline$>80$ years & 3 & 8 & 11 & $5.8 \%$ & $1.6 \%$ \\
\hline Total & 51 & 485 & 536 & $9.51 \%$ & $90.4 \%$ \\
\hline
\end{tabular}

\begin{tabular}{|l|c|c|c|c|c|c|c|}
\hline Age Groups & Oral cavity & Oropharynx & Larynx & Hypopharynx & Nose and PNS & Nasopharynx & p value \\
\hline$<30$ years & 21 & 4 & 1 & 4 & 3 & 0 & $<0.001$ \\
\hline $31-40$ years & 93 & 10 & 7 & 3 & 3 & 1 \\
\hline $41-50$ years & 49 & 23 & 32 & 14 & 6 & 8 \\
\hline $51-60$ years & 41 & 39 & 22 & 25 & 4 & 0 \\
\hline $61-70$ years & 11 & 21 & 29 & 18 & 2 & 0 \\
\hline $71-80$ years & 9 & 3 & 7 & 7 & 2 & 0 \\
\hline$>80$ years & 1 & 9 & 3 & 0 & 1 & 0 \\
\hline Total & 225 & 109 & 101 & 71 & 21 & 9 \\
\hline
\end{tabular}

\begin{tabular}{|l|c|c|c|c|c|c|}
\hline Habit & Buccal mucosa & Oral tongue & Base of tongue & Tonsillar fosse & Larynx & p value \\
\hline Smoking & 15 & 21 & 35 & 51 & 39 & $<0.000$ \\
\hline Chewing & 10 & 5 & 19 & 9 & 19 \\
\hline Smoking + chewing & 13 & 3 & 29 & 11 & 31 \\
\hline Smoking + alcohol & 4 & 7 & 11 & 13 & 21 \\
\hline Smoking + chewing + alcohol & 63 & 8 & 7 & 5 & 11 \\
\hline Chewing + alcohol & 5 & 5 & 8 & 1 & 5 \\
\hline NA (Not any) & 3 & 12 & 10 & 19 & 8 \\
\hline Total & 113 & 61 & 119 & 109 & 134 \\
\hline Table-4: Shows the distribution of data based on the common risk factor in common sites of head and neck cancer among the study \\
\hline
\end{tabular}


has been found from the previous literature that the most common among all head and neck cancers is oral cancer. The head and neck squamous cell carcinoma is quite different in developing world than in the developed world in relation of gender, site of disease, etiology, and molecular biology. The major challenges in management of these cancers are poverty, illiteracy, advanced stage at presentation, lack of access to health care and poor treatment. In developing countries, the annual GDP spent on health care is very less compared to the developed countries. The treatment of cancer leads to a significant financial burden on the cancer patients and their families. ${ }^{13,14}$

The commonest HNCA obtained was oropharyngeal carcinoma comprising of 320 cases $(28.62 \%)$ followed by oesophageal and oral cavity cancers comprising of 217 cases (19.41\%) and 182 cases (16.28\%) respectively. Oropharyngeal carcinoma comprised of $15.56 \%$ of TBM followed by oesophageal cancers (10.6\%). Carcinoma of ear was the least common comprising of $24 \%$ of TBM and $.43 \%$ of HNCA. With respect to oral cavity and oropharynx the commonest site involved was tongue $(32.67 \%)$. Carcinoma cheek and tonsil formed more than $20 \%$ of oral cavity malignancies and about $5 \%$ of TBM. ${ }^{15,16}$

In a study done by Mehrotra et al it was found that male cases were far more common than female comprising of 833 males to 285 females, (2.9:1). Oropharyngeal cancer is commonest in males $(n=253)$ while in females oesophageal cancer was the commonest $(n=76)$. This male: female ratio is higher than in other studies ranging (1.5:1 to $2.1: 1)$. It was investigated that cigarette-smoking and alcohol consumption were found to be the main reasons for head and neck cancers in the population, whereas the use of smokeless tobacco and areca nut is the most common cause of head and neck squamous cell carcinoma in Southeast Asia and these findings are in concordance with the findings of the present study. In developing countries, smokeless tobacco is used in various forms which include khaini, mava, paan (betel quid), zarda, snuff and mashiri, etc. ${ }^{17,18}$

In the Asia-Pacific region, betel quid chewing is considered to be the main type of chewing tobacco. It consists of areca nut, betel leaf, catechu, and slaked lime. It has been reported from many countries like India, Pakistan, Bangladesh, Sri Lanka, Thailand, Cambodia, Malaysia, Indonesia, China, Philippines, Taiwan, Vietnam, and migrant populations in Europe, Africa, North America, and Australia. ${ }^{19}$

Out of the total population, about $10 \%$ of the world's population chew betel quid on a regular basis. In Southeast Asian region, it was observed that there was higher risk of developing head and neck cancer among the individuals with lower socio-economic groups. On the basis of data obtained from the studies in different region of India among head and neck cancer patients, it was found that larynx was most common site of HNC in South India (38.37\%) and Bihar, oral cavity in Uttar Pradesh, and Ahmednagar (41.28\%), and oropharynx in Northeast and Meghalaya $(24 \%) .{ }^{20}$

In this study, oral cancer (225 subjects) was found to be most common HNC and larynx was most common sub site followed by buccal mucosa and base of tongue and these similar findings were observed in the study done by
Rao et al. It has been found that the prevalence of tobacco consumption rises up to the age of 50 years and then there is decrease in Indian population. In this study, maximum number of head and neck cancers are present in 50-60 year of age and $>60 \%$ of HNC were found in $40-60$ year of age. These cancers are one of the most common with wide variations in risk factors, sites of involvement, geographical, and demographic characteristics prevalent in India. ${ }^{21}$

Heterogeneity in risk factors and differences of $\mathrm{HNC}$ at different sites of head and neck region may be because of differences in surface area, microanatomy, tissue microenvironment, and duration of exposure to carcinogens which need to be explored. This study helped to quantify and analyse the spectrum of HNCA and served as a starting point for a much needed population based study in this region. ${ }^{22}$ A combined effort is needed to know the cause of such high prevalence, generate awareness and treatment options suited to meet this challenge.

\section{CONCLUSION}

In North western region, head and neck cancers is one of the prevalent cancer with huge variations in geographical and demographical characteristics risk factors, sites of involvement.

\section{REFERENCES}

1. Franceschi S,Bidoli P,Herrero R,Munoz N.Comparison of cancers of the oral cavity and pharynx worldwide: Etiological clues. Oral Oncol 2000; 36(1):106-15.

2. Elango JK, Gangadharan P, Sumithra S, Kuriakose MA. Trends of head and neck cancers in urban and rural India. Asian Pac J Cancer Prev 2006; 7(2):108-12.

3. Bhattacharjee A, Chakraborty A, Purkaystha P. Prevalence of head and neck cancers in the North East An institutional study. Indian J Otolaryngol Head Neck Surg 2006; 58(6):15-9.

4. Mehrotra R, Singh M, Gupta RK, Singh M, Kapoor AK. Trends of prevalence and pathological spectrum of head and neck cancers in North India. Indian J Cancer 2005; 42(5):89-93.

5. Shinde KJ,Hashmi SI. Retrospective study of malignant lesions of head \& neck in rural area of Ahmednagar district. IOSR J Dent Med Sci 2013(3); 4:12-9.

6. WHO 2008. The global burden of disease: 2004 update. Available at: www.who.int/evidence/bod (accessed January 3, 2020 at 11:00p.m).

7. Sankaranarayanan R, Masuyer E, Swaminathan R, Ferlay J, Whelan S. Head and neck cancer: a global perspective on epidemiology and prognosis. Anticancer Res. 1998; 18(2):4779-86.

8. Bhatia PL, Jha BK. Pattern of head and neck cancer in Manipur. Indian J Cancer 1982; 19(5):241-8.

9. Padmanabhan TK, Vasudevan DM. A statistical analysis of cancer registered at the Regional Cancer Centre, Trivandrum. Indian J Cancer 1982; 19(3):189-96.

10. Jussawalla DJ, Sathe PV, Yeole BB, Natekar MV. Cancer incidence in Aurangabad city 1978-1980. Indian J Cancer 1984; 21(1):55-62.

11. Thakur S, Chaturvedi VN, Singh AK, Puttewar MP, Raizada RM. Pattern of ear, nose, pharynx, larynx and 
oesophagus(enplo) cancers in a rural based hospital. Indian J Otolaryngol Head Neck Surg 2001; 53(6):93-9.

12. WHO. Tobacco or Health: A Global Status Report. Geneva: World Health Organization; 1997. Accessed on $4^{\text {th }}$ January 2020 at 3:00 p.m.

13. Elango KJ, Suresh A, Erode EM, Subhadradevi L, Ravindran HK, Iyer SK, et al. Role of human papilloma virus in oral tongue squamous cell carcinoma. Asian Pac J Cancer Prev 2011; 12(2):889-96.

14. Angadi PV, Rao SS. Areca nut in pathogenesis of oral submucous fibrosis: revisited. Oral Maxillofac Surg 2011; 15(5):1-9.

15. Rajalalitha P, Vali S. Molecular pathogenesis of oral submucous fibrosis-a collagen metabolic disorder. J Oral Pathol Med 2005; 34(5):321-8.

16. Sunny L, Yeole BB, Hakama M, Shiri R, Sastry PS, Mathews $\mathrm{S}$, et al. Oral cancers in Mumbai, India: a fifteen years perspective with respect to incidence trend and cumulative risk. Asian Pac J Cancer Prev 2004; 5(2):294-300.

17. Mehrotra R, Singh M, Kumar D, Pandey AN, Gupta RK, Sinha US. Age specific incidence rate and pathological spectrum of oral cancer in Allahabad. Indian J Med Sci 2003; 57(1):400-4.

18. Jandoo T, Mehrotra R. Tobacco control in India: present scenario and challenges ahead. Asian Pac J Cancer Prev 2008; 9:805-10.

19. Murray CJL, Lopez AD. The Global Burden of Disease: A Comprehensive Assessment of Mortality and Disability from Diseases, Injuries, and Risk Factors in 1990 and Projected to 2020. Boston: Harvard University Press; 1996.

20. Jha P, Chaloupka FJ. Curbing the Epidemic: Governments and Economics of Tobacco Control. Washington, DC: World Bank; 1999.

21. Rao M, Rao KD, Shiva Kumar AK, Chatterjee M, Sundarraraman T. Human resources for health in India. Lancet 2011; 377(2):587-98.

22. Sarin R. Indian National Cancer Control Programme: setting sight on shifting targets. J Cancer Res Ther 2005; $1(5): 240-8$.

Source of Support: Nil; Conflict of Interest: None

Submitted: 21-07-2019; Accepted: 16-08-2019; Published online: 19-12-2019 